\title{
A case series of complicated infective otitis media requiring surgery in adults
}

\author{
Harold $\underline{\text { Heah }}^{1}$, mBBs, MMed, Sue Rene $\underline{\text { Soon }}^{2}$, mBBs, MMed, Heng-Wai Yuen ${ }^{3}$, MBBS, MMed
}

\begin{abstract}
INTRODUCTION With the advent of antibiotics, complications of otitis media have become less common. It is crucial for physicians to recognise otitis media and treat its complications early. Herein, we present our institution's experience with patients who required emergency surgical intervention for complications of otitis media.

METHODS Data on patients who underwent emergency surgery for complications of otitis media from 2004 to 2011 was retrieved from the archives of the Department of Otolaryngology, Changi General Hospital, Singapore.

RESULTS A total of 12 patients (10 male, two female) underwent emergency surgery for complications of otitis media. The median age of the patients was 25 years. Otalgia, otorrhoea, headache and fever were the main presenting symptoms. Extracranial complications were observed in 11 patients, and six patients had associated intracranial complications. The primary otologic disease was acute otitis media in six patients, chronic otitis media without cholesteatoma in three patients and chronic otitis media with cholesteatoma in three patients. Mastoidectomy and drainage of abscess through the mastoid, with insertion of grommet tube, was the main surgical approach. Two patients required craniotomy. The mean length of hospital stay was 16.2 days and the mean follow-up period was 16.3 months. Five patients had residual conductive hearing loss; two patients with facial palsy had full recovery.

CONCLUSION Otitis media can still result in serious complications in the post-antibiotic era. Patients with otitis media should be monitored, and prompt surgical intervention should be performed when necessary to attain good outcomes.
\end{abstract}

Keywords: abscess, complications, mastoiditis, middle ear, otitis media

\section{INTRODUCTION}

Otitis media is a common condition. The reported incidence of acute otitis media ranges from $2.8 \%$ to $4.4 \%$. ${ }^{(1)}$ Patients with acute otitis media are often young, with the incidence of the disease in children reported to be as high as $10.6 \% .^{(2)}$ In contrast, the disease is less commonly seen in adults; the reported incidence of purulent otitis media in adults was only $0.25 \%$. $^{(1)}$

With the advent of antibiotics and advances in surgical care, morbidity associated with otitis media has declined over the years. ${ }^{(3)}$ Nevertheless, intracranial and extracranial complications can still occur, and are associated with significant morbidity and mortality. ${ }^{(4,5)}$ While complications of otitis media in the paediatric population have been widely published in the literature, there have been very few studies reporting complications of otitis media in the adult population. Herein, we present our experience of managing complications of otitis media in adult patients.

\section{METHODS}

This study was a retrospective review of the archives of the Department of Otolaryngology, Changi General Hospital, Singapore. We performed a manual search of the department's surgical records and the hospital's electronic admission records. The clinical charts of patients aged $\geq 16$ years who had otitis media with clinical or radiological evidence of complications (either intracranial or extracranial) and who underwent emergency surgical intervention between April 2004 and February
2011 were retrieved. Patient demographics, presentation, clinical course, investigations, management and postoperative outcomes were analysed. Ethics approval was obtained from the hospital's Institutional Review Board.

\section{RESULTS}

A total of 12 patients (10 male, two female) had otitis media with clinical or radiological evidence of complications (either intracranial or extracranial) and underwent surgical intervention between April 2004 and February 2011. The median age of the patients was 25 (range 16-74) years. The characteristics of the patients are summarised in Table I.

The presenting symptoms of the patients included otalgia $(n=9)$, otorrhoea $(n=7)$, fever $(n=5)$ and headache $(n=3)$ (Table II). One patient experienced unsteady gait two weeks prior to presentation, and one patient had significant nausea and vomiting for three days prior to presentation. One patient had only fever with nausea and vomiting, with no otologic symptoms. The mean duration of symptoms was 13.2 days. Physical signs that were observed among the 12 patients included swollen and tender mastoid regions, inflammatory polyps and granulation tissue in the external auditory canal, perforated tympanic membrane with purulent otorrhoea, and attic tympanic membrane retraction with squames. In addition, two patients had associated lower motor neuron facial nerve palsy (House-Brackmann Grades III and IV).

${ }^{1}$ Department of Otolaryngology, Singapore General Hospital, ${ }^{2}$ Department of Otolaryngology, Ng Teng Fong General Hospital, ${ }^{3}$ Department of Otolaryngology, Changi General Hospital, Singapore 
Table I. Characteristics of the 12 patients who required emergency surgical intervention for complications of otitis media.

\begin{tabular}{|c|c|c|c|c|c|c|c|}
\hline \multirow[t]{2}{*}{ Case } & \multirow[t]{2}{*}{ Gender } & \multirow{2}{*}{ Age (yr) } & \multirow{2}{*}{$\begin{array}{l}\text { Primary } \\
\text { disease }\end{array}$} & \multicolumn{2}{|c|}{ Complications } & \multirow[t]{2}{*}{ Operation performed } & \multirow[t]{2}{*}{ Organism grown } \\
\hline & & & & Extracranial & Intracranial & & \\
\hline 1 & Male & 66 & $\mathrm{AOM}$ & Mastoiditis & $\begin{array}{l}\text { Temporal lobe } \\
\text { abscess }\end{array}$ & $\mathrm{CM}$, craniotomy, MT & Klebsiella pneumoniae \\
\hline 2 & Male & 21 & AOM & Mastoiditis & - & $\mathrm{CM}, \mathrm{MT}$ & - \\
\hline 3 & Female & 16 & $\mathrm{AOM}$ & $\begin{array}{l}\text { Mastoiditis, subperiosteal } \\
\text { abscess }\end{array}$ & - & $\mathrm{CM}$ & - \\
\hline 4 & Male & 30 & COMC & Facial nerve palsy & - & MRM, FND & Pseudomonas aeruginosa \\
\hline 5 & Male & 22 & AOM & $\begin{array}{l}\text { Mastoiditis, subperiosteal } \\
\text { abscess }\end{array}$ & - & $\mathrm{CM}, \mathrm{MT}$ & Klebsiella pneumoniae \\
\hline 6 & Male & 74 & $\mathrm{AOM}$ & $\begin{array}{l}\text { Mastoiditis, facial nerve } \\
\text { palsy }\end{array}$ & - & CM, FND & Pseudomonas aeruginosa \\
\hline 7 & Female & 17 & COM & $\begin{array}{l}\text { Mastoiditis, subperiosteal } \\
\text { abscess }\end{array}$ & - & $\mathrm{CM}$ & Group A streptococcus \\
\hline 8 & Male & 45 & COMC & Mastoiditis & $\begin{array}{l}\text { Extradural abscess, } \\
\text { sinus thrombosis }\end{array}$ & CM, revision MRM, MT & Proteus mirabilis \\
\hline 9 & Male & 17 & AOM & $\begin{array}{l}\text { Mastoiditis, subperiosteal } \\
\text { abscess }\end{array}$ & Extradural abscess & $\mathrm{CM}$ & Streptococcus pneumoniae \\
\hline 10 & Male & 35 & COMC & $\begin{array}{l}\text { Mastoiditis, subperiosteal } \\
\text { abscess }\end{array}$ & Extradural abscess & MRM & Proteus mirabilis \\
\hline 11 & Male & 25 & COM & $\begin{array}{l}\text { Mastoiditis, subperiosteal } \\
\text { abscess }\end{array}$ & $\begin{array}{l}\text { Sinus thrombosis, } \\
\text { temporal-occipital } \\
\text { lobe abscess }\end{array}$ & $\begin{array}{l}\mathrm{CM}, \mathrm{MT} \text {, craniotomy, } \\
\text { revision MRM }\end{array}$ & Streptococcus milleri \\
\hline 12 & Male & 67 & COM & $\begin{array}{l}\text { Mastoiditis, subperiosteal } \\
\text { abscess }\end{array}$ & Sinus thrombosis & $\mathrm{CM}, \mathrm{MT}$ & $\begin{array}{l}\text { Group B streptococcus, } \\
\text { Streptococcus milleri }\end{array}$ \\
\hline
\end{tabular}

AOM: acute otitis media; CM: cortical mastoidectomy; COM: chronic otitis media; COMC: chronic otitis media with cholesteatoma; FND: facial nerve decompression; MRM: modified radical mastoidectomy; MT: myringotomy and grommet tube

Table II. Clinical characteristics of the patients $(n=12)$.

\begin{tabular}{lc}
\hline Variable & No. (\%) \\
\hline Symptom & $9(75.0)$ \\
Otalgia & $7(58.3)$ \\
Otorrhoea & $5(41.7)$ \\
Fever & $3(25.0)$ \\
Headache & $2(16.7)$ \\
Facial nerve palsy & $1(8.3)$ \\
Nausea/vomiting & $1(8.3)$ \\
Unsteady gait & \\
Sign & $6(50.0)$ \\
Swollen, tender mastoid & $5(41.7)$ \\
Inflammatory polyps/granulations in EAC & $4(33.3)$ \\
Suppurative otitis media & $1(8.3)$ \\
Attic retraction pocket with squames & $2(16.7)$ \\
None &
\end{tabular}

EAC: external auditory canal

Preoperative pure-tone audiograms were available for nine of the 12 patients; the remaining three patients were unable to undergo pure-tone audiometric assessment, as two were septic and one was non-communicative. The preoperative pure-tone audiograms of eight of the nine patients showed ipsilateral conductive hearing loss with air-bone gaps ranging from 10-40 dB HL.

Among the 12 patients, four had underlying type II diabetes mellitus and were already on oral hypoglycaemic agents at the time of presentation. Two of them had good glycaemic control with normal HbA1c levels, while the other two had elevated HbA1c levels. No other underlying medical conditions that would have predisposed the patients to infection or immunocompromised states were noted. In ten patients, ear swab cultures revealed a variety of aerobic and anaerobic bacteria (Table I). No bacterial growth was observed in the ear swab cultures of two patients. The patients' antibiotic regimens were tailored according to the sensitivity results.

All 12 patients underwent computed tomography (CT) of the temporal bone. Two patients underwent subsequent magnetic resonance imaging (MRI) studies. The diagnosis of otitis media with complications was made based on the patients' clinical presentation and imaging results. The primary otologic disease was identified to be acute otitis media in six patients, chronic otitis media without cholesteatoma in three patients and chronic otitis media with cholesteatoma in three patients. Six patients were found to have intracranial complications on imaging - two patients had cerebral abscesses, three had sinus thromboses and three had extradural abscesses (Fig. 1; Table III). Extracranial complications were observed in 11 patients; all 11 had mastoiditis, while seven had subperiosteal abscesses (Fig. 2).

All the patients were treated with intravenous antibiotics and underwent surgical drainage. Two patients required intensive care support at presentation. Cortical mastoidectomies were performed for ten patients. Five of these patients also had concurrent myringotomy and grommet tube insertions. The three patients who had cholesteatoma underwent modified radical mastoidectomies. For the two patients who had facial 


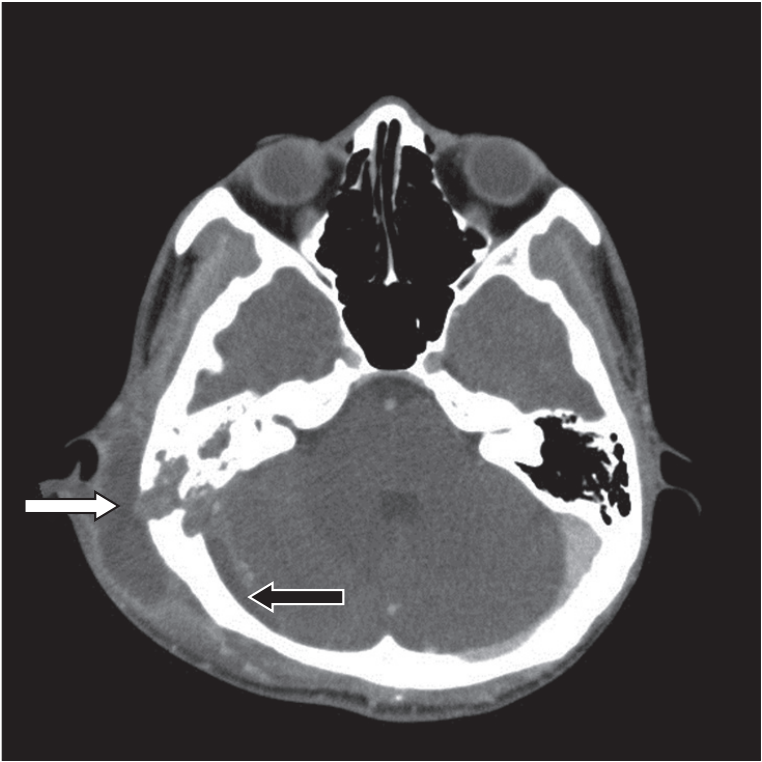

Fig. 1 Gadolinium-contrast MR image of a 25-year-old man, who presented with one month of otorrhoea and fever without any localising neurological signs, shows right mastoiditis (white arrow). Adjacent to the mastoiditis is a loculated, extra-axial fluid collection with enhancing wall overlying the right posterior cerebral hemisphere, in keeping with an extradural abscess (black arrow).

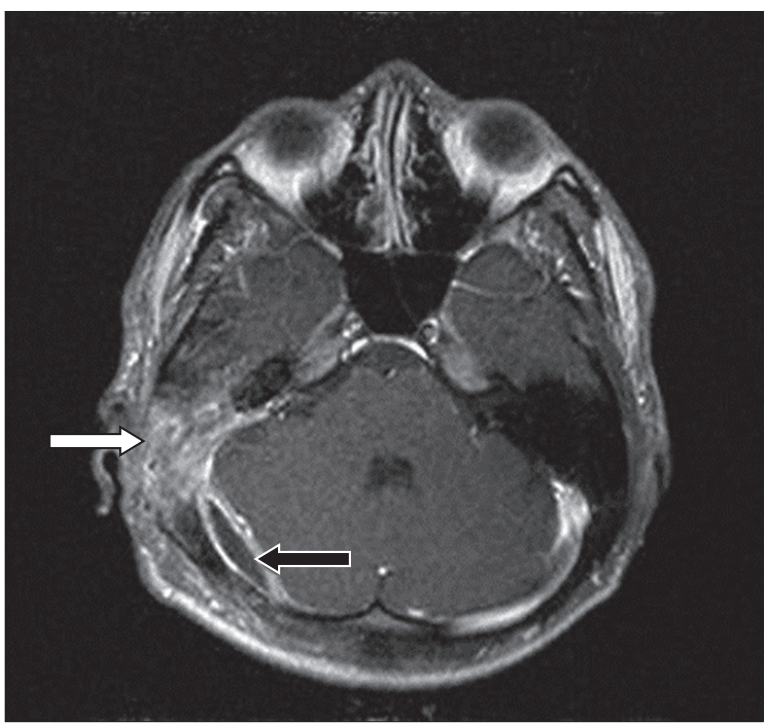

Fig. 2 CT image with contrast shows bony destruction of the right mastoid bone, in keeping with mastoiditis. Erosion of the outer cortex of the mastoid bone and the presence of a subperiosteal abscess (white arrow) is seen. An intracranial extension with an extradural collection over the right temporal and occipital lobes (black arrow) is also seen.

Table III. Intracranial and extracranial complications of otitis media observed among the patients $(n=12)$.

\begin{tabular}{lc}
\hline Complication & No. (\%) \\
\hline Intracranial $(\mathbf{n}=\mathbf{6})$ & $2(16.7)$ \\
Brain abscess & $3(25.0)$ \\
Sinus thrombosis & $3(25.0)$ \\
Extradural abscess & \\
Extracranial $(\mathbf{n}=\mathbf{1 1})$ & $11(91.7)$ \\
Mastoiditis & $7(58.3)$ \\
Subperiosteal abscess & $2(16.7)$ \\
Facial nerve palsy
\end{tabular}

nerve palsy, concurrent surgical decompression of the vertical segment of the facial nerve was performed. The two patients with cerebral abscesses underwent burr hole craniotomies and drainage of the cerebral abscesses. One patient had subsequent revision mastoidectomy, as he was found to have a residual cholesteatoma at follow-up, six weeks after the initial operation.

There was no mortality in our series. The mean length of hospital stay was 16.2 days and the mean follow-up period was 16.3 months. Three patients experienced wound dehiscence, which was successfully treated with regular wound dressings and oral antibiotics (i.e. conservative treatment). The six patients who had intracranial complications recovered well with no permanent neurological sequelae. The two patients who had facial nerve palsy at presentation experienced full recovery of their facial nerve function within nine months. The three patients who had chronic otitis media with cholesteatoma were followed up for more than 14 months, with no evidence of recurrent disease.

\section{DISCUSSION}

Complications of otitis media may result from acute otitis media or acute exacerbation of chronic otitis media. The reported overall incidence of complications from chronic otitis media ranges from $0.7 \%$ to $3.5 \%$. ${ }^{(6)}$ The low incidence of morbidity from otogenic infections has been attributed to improved access to healthcare, increased usage of antibiotics by primary care physicians, and improved standards of hygiene and quality of life. ${ }^{(5)}$

In a study conducted by Dubey and Larawin, $85 \%$ of the patients with complications arising from chronic suppurative otitis media were aged less than 30 years. ${ }^{(7)}$ This disease was also observed among patients in this specific age group in other studies in the literature. ${ }^{(3,8)}$

With the increased use of antibiotics, physicians should be aware that patients may not present with florid symptoms and signs that are suggestive of complications of otitis media. Patients may have had their mastoiditis partially treated with broad-spectrum antibiotics, and present with minimal otological symptoms and vague neurological signs and symptoms; in such cases, Holt and Gates described the clinical entity as 'masked mastoiditis'. ${ }^{(9)}$ In the present study, one patient experienced no otological symptoms and two patients had a paucity of clinical findings. Furthermore, complications such as the presence of brain abscess and/or subperiosteal abscess could only be confirmed after imaging. Thus, we suggest that a thorough otological history be taken and a physical examination performed for patients suspected to have complications of otitis media, especially if they are young or have a compromised immune system.

Mastoiditis was the most commonly encountered extracranial complication in the present study. This is not surprising, given that the most direct pathway of middle ear infection extends posteriorly to the mastoid air cells, and no osseous barriers lie in this pathway. Direct extension of the infection can result in subperiosteal abscess formation, as was seen in seven of our patients. The presence of a fistula from the mastoid air cells to the subperiosteal abscess can help to decompress the middle ear cleft and, in turn, lower the 
chance of intracranial complication. ${ }^{(7)}$ Nevertheless, this was not observed in the present study, as the patients were found to have intracranial complications in the presence of subperiosteal abscess.

Transverse sinus thrombosis was diagnosed on MRI, MR angiography or contrast CT in three of the 12 patients in our series. The management of sinus thrombosis is controversial, as the role of anticoagulation and thrombectomy in sinus thrombosis is still being debated. In general, early treatment with broad-spectrum antibiotics and concurrent cortical mastoidectomy is regarded as appropriate. ${ }^{(10)}$ We concur with the general recommendation that treatment should be directed toward the primary site of infection (i.e. the middle ear and mastoid air cells) to remove the precipitating cause. However, ligation of the internal jugular vein or open thrombectomy should be considered in cases with extensive progression of thrombosis, even though these procedures are not without morbidity. In the present study, the three patients who had transverse sinus thrombosis showed improvement (i.e. resolution of sinus thrombi on follow-up imaging studies) without the use of anticoagulation or surgical evacuation of sinus thrombi.

In the literature, the most common site of brain abscess formation is reported to be the ipsilateral temporal lobe. ${ }^{(8,11)}$ In the present study, two patients had cerebral abscesses - one had a temporal lobe abscess, while the other had abscesses affecting the cerebellum and occipital lobes. Both patients obtained their scans within 48 hours of presentation, and had emergency burr hole and drainage of abscess performed within 24 hours of diagnosis.

While some authors have suggested a period of conservative treatment with intravenous antibiotics for otogenic brain abscesses, ${ }^{(11)}$ we opine that otogenic brain abscesses should be urgently managed by the neurosurgeon and neuro-otologist. We advocate the initiation of broad-spectrum intravenous antibiotics and emergent surgical drainage, as mortality from otogenic brain abscesses was reported to be $26 \%$ in a recent series, with the high rate of mortality attributed to late diagnosis and treatment. ${ }^{(12)}$ There were no deaths in the present study, possibly due to early diagnosis and early surgical intervention. Interestingly, meningitis, which is the most common intracranial complication reported in the literature, was not observed in our series.

Facial nerve palsy was observed in two of our patients - one had chronic otitis media with cholesteatoma, while the other had acute otitis media without cholesteatoma. Facial nerve palsy in acute otitis media is believed to be a result of oedema of the nerve within the bony canal and neuritis. Hence, treatment should be largely conservative, comprising antibiotics, and perhaps myringotomy and grommet tube insertion. ${ }^{(4,13)}$ In the case of chronic otitis media with facial nerve palsy, early cortical mastoidectomy with careful removal of the diseased tissue around the nerve is advocated. ${ }^{(5)}$ Both of our patients underwent surgical decompression of the facial nerve and had complete recovery. One patient presented six days after the onset of facial paresis and was found to have a dehiscent horizontal segment of the facial nerve; the other patient presented three weeks after the onset of facial paresis and was found to have erosion of the vertical segment of the facial nerve intraoperatively. The first patient experienced complete recovery within one month, while the latter experienced complete recovery only after nine months. It is unclear whether surgical decompression and the timing of the surgery played a major role in the recovery of the facial nerve.

The role of mastoidectomy in the treatment of otitis media with complications is well established. The purpose would be to determine the underlying pathology (e.g. a previously undiagnosed cholesteatoma) and control the disease process. ${ }^{(11)}$ While the extent of surgery is controversial, canal-wall-up mastoidectomy is advocated by several authors; more radical surgery is reserved for cases with cholesteatoma. ${ }^{(14-16)}$ In the present study, cortical mastoidectomy was performed for most of the patients, while modified radical mastoidectomy was performed for patients who had underlying cholesteatoma.

During follow-up after surgery, the patients underwent otoscopic examination, pure-tone audiogram and repeat $\mathrm{CT}$ to check if there were findings suggestive of residual or recurrent disease. One of the patients had to undergo revision mastoidectomy six weeks after his initial surgery, as he had persistent otorrhoea secondary to residual cholesteatoma. This is not uncommon, as pathology is sometimes obscured by bleeding, pus and granulation tissue during emergent surgical intervention. We propose that all patients who have undergone treatment for complications of middle ear disease be followed up in the outpatient clinic until the middle ear is dry and well aerated; repeat CT should be ordered if otorrhoea persists.

The main morbidity encountered in the present study was that of persistent conductive hearing loss. This was observed in five of our patients and was secondary to ossicular chain erosion. The severity of hearing loss was 10-40 dB HL, with air-bone gaps in the frequencies of $0.5-2 \mathrm{kHz}$. Hearing restoration procedures were offered to these five patients, but they declined any further surgery.

Despite the advent and accessibility of antibiotic therapy, complications arising from otitis media can still occur in young adults and in developed countries. Although rare, these complications are associated with significant morbidity and even mortality, if diagnosis is not made expeditiously and treatment is not instituted early. A high index of suspicion is needed; clinicians should be vigilant in looking out for swelling in the mastoid region, facial nerve weakness and neurological symptoms such as nausea and vomiting. Early treatment with directed antimicrobial therapy, a multidisciplinary surgical approach that includes mastoidectomy, and, if necessary, neurosurgical intervention (e.g. drainage of brain abscess) allow for good outcomes in patients with complications of otitis media.

\section{REFERENCES}

1. Schwartz LE, Brown RB. Purulent otitis media in adults. Arch Intern Med 1992; 152:2301-4.

2. Lowe JF, Bamforth JS, Pracy R. Acute otitis media. One year in a general practice. Lancet $1963 ; 2: 1130-2$.

3. Hafidh MA, Keogh I, Walsh RM, Walsh M, Rawluk D. Otogenic intracranial 
complications. A 7-year retrospective review. Am J Otolaryngol 2006; 27:390-5.

4. Leskinen K, Jero J. Acute complications of otitis media in adults. Clin Otolaryngol 2005; 30:511-6.

5. El-Kashlan HK, Harker LA, Shelton C, Aygun N, Niparko JK. Complications of temporal bone infections. In: Flint PW, Haughey BH, Lund VJ, Niparko JK, eds. Cummings Otolaryngology Head \& Neck Surgery. 5th ed. Philadelphia: Mosby-Elsevier, 2010: 1979-98.

6. Lin YS, Lin LC, Lee FP, Lee KJ. The prevalence of chronic otitis media and its complication rates in teenagers and adult patients. Otolaryngol Head Neck Surg 2009; 140:165-70.

7. Dubey SP, Larawin V. Complications of chronic suppurative otitis media and their management. Laryngoscope 2007; 117:264-7.

8. Penido Nde O, Borin A, Iha LC, et al. Intracranial complications of otitis media: 15 years of experience in 33 patients. Otolaryngol Head Neck Surg 2005; 132:37-42.
9. Holt GR, Gates GA. Masked mastoiditis. Laryngoscope 1983; 93:1034-7.

10. Ropposch T, Nemetz U, Braun EM, et al. Management of otogenic sigmoid sinus thrombosis. Otol Neurotol 2011; 32:1120-3.

11. Wanna GB, Dharamsi LM, Moss JR, et al. Contemporary management of intracranial complications of otitis media. Otol Neurotol 2010; 31:111-7.

12. Osma U, Cureoglu S, Hosoglu S. The complications of chronic otitis media: report of 93 cases. J Laryngol Otol 2000; 114:97-100.

13. Popovtzer A, Raveh E, Bahar G, et al. Facial palsy associated with acute otitis media. Otolaryngol Head Neck Surg 2005; 132:327-9.

14. Singh B, Maharaj TJ. Radical mastoidectomy: its place in otitic intracranial complications. J Laryngol Otol 1993; 107:1113-8.

15. Felisati G, Di Berardino F, Maccari A, Sambataro G. Rapid evolution of acute mastoiditis: three case reports of otogenic meningitis in adults. Am J Otolaryngol 2004; 25:442-6.

16. Samuel J, Fernandes CM, Steinberg JL. Intracranial otogenic complications: a persisting problem. Laryngoscope 1986; 96:272-8. 